\title{
Using Problem-Solving Videos in an Introductory Engineering Circuit Analysis Course
}

\author{
R. M. Nelms, R. F. Halpin \\ Auburn University/Program Evaluation and Assessment Consultants \\ nelms@eng.auburn.edu
}

Introduction

Even though research has been conducted in the university classroom in an effort to evaluate and improve different teaching methods in the presence of ever-changing technology ${ }^{1-3}$, the investigation of how to improve students' problem-solving skills through the use of study tools needs further investigation. The technology reform movement has led to changes in how instructors of engineering material teach the content and has forced instructors to change their teaching methods ${ }^{4-7}$. Educators are now generally agreed that it is possible to improve students' problem-solving skills through carefully selected instructional practices. But what about providing instructional aids to improve students' study procedures outside of class? In support of this effort, the learning theory known as constructivism has been applied as changes are made in the way engineering courses are being taught using technology-based instructional aids. The constructivist reform links directly to the accepted educational philosophies of John Dewey Piaget, and Bruner ${ }^{8-10}$, which support students developing their own understanding by integrating new information to their own prior knowledge and experiences. While the constructivist approach to teaching focuses on problem solving, thinking skills, and learning strategies, the focus relevant to the engineering classroom in terms of study tools is the emphasis on the students' abilities to solve practical problems using their own problem-solving skills and at their own pace rather than on instructional sequences that require memorization of certain content material. Based on the constructivist theory, the creation of meaningful connections evolves by providing students time to explore relevant problems and to be involved in learning environments that engage the students in developing their own knowledge base. Therefore, when the instructor provides the necessary resources that encourages the students to develop their own problem-solving skills, this promotes retention of the material as opposed to the students relying only on the instructor's coverage of the material which promotes rote memorization 6,8 .

During the past decade, the use of technology in a constructivist environment has focused on the development of computational software or visual representations that students can use to solve problems ${ }^{11-15}$. Regardless of how technology is being used in the classroom as an instructional tool, it is still imperative to the student to receive numerous examples with step-bystep explanations from the instructor that can be used while completing homework outside of class or studying for tests. The question, however, is how can the instructor provide students immediate assistance outside of class to assist their studying procedures? While there are

"Proceedings of the 2005 American Society for Engineering Education Annual conference \& Exposition Copyright@ 2005, American Society for engineering Education", 
questions from the students in class, it is not until they are outside of class studying the material that they discover they could benefit if they had the verbal explanation from the instructor they vaguely recall from class or a verbal explanation of how to work a similar problem for the concepts they are currently studying or trying to apply to their own homework problem. The motivation for the current project was to provide students with study tools that would assist them as they studied the material at their own pace and that would facilitate them in developing their own problem-solving skills. Discussed in this paper is the use of problem-solving videos (PSVs), available via the Internet, as a study tool for students in an introductory engineering circuit analysis course. The instructor prepared videos, with audio, of the step-by-step solutions for the following course materials: 1) all examples worked in the classroom, 2) extra examples not worked in the classroom, 3) graded homework assignments, and 4) examinations. In addition, video solutions for homework and examinations from previous semesters were made available to the students as a study tool that they could use at their own pace as they were developing their own understanding of the material. As a result, students were able to repetitively review the solution of classroom examples while reviewing their course notes. Homework and exam solutions were not presented during class time; students were encouraged to examine those solutions at their own convenience, make their own conclusions, and to visit with the instructor to discuss any questions. The time normally devoted to reviewing homework and exam solutions in class was utilized to present additional course materials.

This project began with PSVs for homework and class problems being worked and explained by the instructor and then provided via the Internet to an introductory engineering circuit analysis class. The descriptive evaluation was to determine if the PSVs were considered by the students as a beneficial study tool and provide baseline date on how the students were using the PSVs as study tools. The research questions guiding this descriptive study were: 1) how frequently will students use the PSVs?, 2) how do students report using the PSVs as a study tool?, 3) how will students use the PSVs to study for tests and complete their homework?, 4) will students use the PSVs as a tool for reviewing and studying the material in a repetitive, step-by-step approach?, and 5) what are students' suggestions for improvement?

\section{Problem-Solving Video Creation}

Personal computer technology has advanced rapidly in the past few years. Technologies for video and audio capture have also advanced in this same time period. Driven by consumer demand to capture video and audio from sources such as camcorders, many companies have developed inexpensive and easy-to-use hardware and software for this purpose. There are capture cards for installation into desktop PCs and stand-alone capture devices for use with laptop computers. Many of these cards and devices, bundled with software, can be purchased for under US \$200. Three goals were considered before selecting hardware and software for creating the PSVs.

1. It was desirable to have the PSVs be as similar as possible to an instructor working problems on a whiteboard in a classroom. It was decided that it was not important to have the instructor visible in the videos - only that the student could hear and see the step-by-step solution provided by the instructor.

2. Files containing captured video and audio can be quite large. It was important to produce PSVs that were as small as possible.

"Proceedings of the 2005 American Society for Engineering Education Annual conference \& Exposition Copyright $\odot$ 2005, American Society for engineering Education" 
3. It was desirable to produce PSVs in a common format that can be played using Microsoft Windows Media Player ${ }^{\circledR}$, Apple Quick Time ${ }^{\circledR}$, or other video player. Students can download free versions of such software so that they are not required to purchase any specialty software.

Since it was not considered essential for the instructor to be visible in the PSVs, a Samsung SVP-6000 Video Presenter, shown in Figure 1, was utilized to begin the process of making the PSVs. It is an optical device that is capable of projecting transparencies as well as opaque materials and can be used for a variety of applications such as presentations at business meetings, announcements at academic societies, and lecturing at educational institutes. The display functions support the full range of SXGA, XGA, SVGA, and VGA output modes, allowing display on an LCD projector or PC monitor. Composite video and stereo audio outputs are located on the back of the video presenter. In addition, the S-video output terminal on the back of the device allows images to be sent directly to a television or VCR. The pick-up device is a $1 / 2$ " 1.5 million pixel CCD yielding effective pixels of 1360 (horizontal) x 1024 (vertical) and a frame rate of 7.5 frames per second.

All circuit diagrams and problem statements were prepared on plain white paper and were generated using a computer or handwritten. Step-by-step solutions for all problems were then worked under the camera on the Samsung SVP-6000. Only the instructor's hand was visible during the step-by-step solution. The Samsung SVP-6000 converted the step-by-step solution into 'raw' video as the fist step in creation of the PSVs.

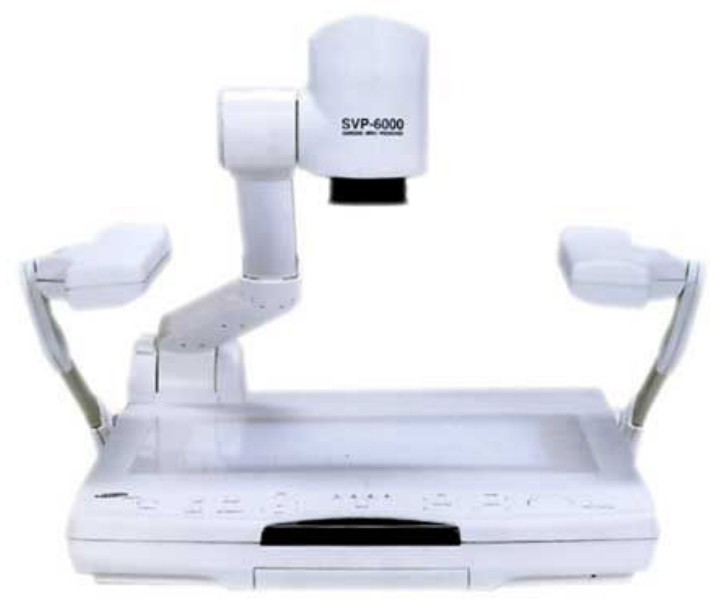

Figure 1. Samsung SVP-6000

The Samsung Video Presenter is just one component in the setup for capturing 'raw' video as shown in Figure 2. The composite video output of the presenter is connected to the video capture device. The stereo inputs of the capture device are connected to an amplifier that receives a signal from a microphone. The very common electret microphones utilized with many personal computers do not have sufficient output to drive the stereo inputs on many capture devices. The video and audio are automatically synchronized because they are acquired simultaneously by the capture device. Most capture devices require a USB 2.0 connection to a laptop computer to operate effectively.

"Proceedings of the 2005 American Society for Engineering Education Annual conference \& Exposition Copyright@ 2005, American Society for engineering Education" 


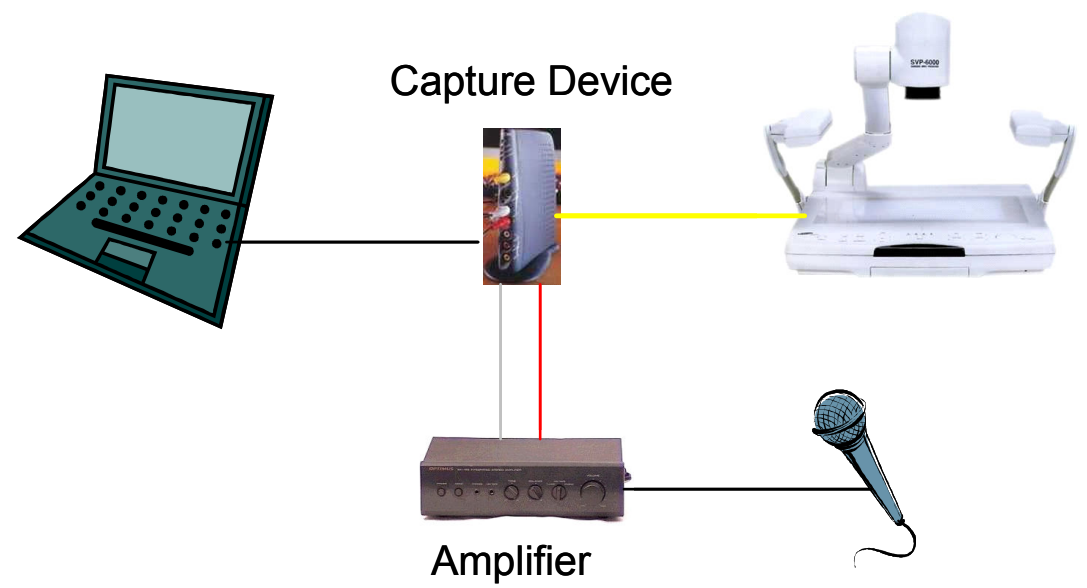

Figure 2. PSV capture setup.

Software on the laptop computer controls the capture device and stores the 'raw' video, including audio, on the laptop hard drive. Most software bundled with capture devices have the capability to store the 'raw' video in MPEG-1 or MPEG-2 format. Capture in MPEG-4 format is available with some software packages. At this point in the PSV creation process, the 'raw' video files are quite large. As examples, 3 minute and 30 second (3:30) and 16:55 MPEG-2 videos, in MPEG-2 format, have file sizes of 133.9 MB and 649.6 MB, respectively. The size of these files limits their usefulness over the internet. However, the software packages have an option, typically labeled 'Make Movie', that converts the MPEG video file into a format that can be played using any of the common video players such as Microsoft Windows Media Player ${ }^{\circledR}$, Apple Quick Time ${ }^{\circledR}$, or Real Networks Real Player ${ }^{\circledR}$. This conversion process results in a much smaller file. Converting the 3:30 MPEG-2 video file into a Windows Media file(wmv extension) yields a file size of 5.9 MB; the 16:55 video file is reduced to $28.2 \mathrm{MB}$ when converted to a Windows Media file. These files are much smaller than the MPEG files but still require the use of a high-speed internet connection such as DSL, cable modem, or those found on many university campuses. Experience has shown that dial-up modem connections are ineffective for accessing the PSVs.

\section{Descriptive Evaluation}

This descriptive study consisted of quantitative (measurable) and qualitative (open-ended) data using surveys to determine the effectiveness of the PSVs as study tools. The quantitative data was summarized and reported using descriptive statistics. The qualitative data was summarized and reported using content analyses. The researcher-developed surveys consisted of five sections. The first section gathered the demographic information and the second section consisted of six statements for the students to rate on a scale of 1 (Poor) to 4 (Excellent) regarding the quality of the PSVs (e.g. picture quality, sound quality, accessibility). The third section was a listing of the five different purposes for which the step-by-step solution PSVs had been developed by the instructor. The students were asked to check all of the different video options (i.e. previous homework, class examples, previous tests, examples not covered in class, and homework solutions from the current semester) they had used as part of their studying of the course material. The fourth section was questions and statements the students rated on a scale of 1 (Never or Disagree) to 4 (Always or Agree) to determine the students' perceptions of the 
effectiveness of the PSVs as a study tool and the study procedures they applied while using the PSVs. The last section provided the students the opportunity to give more details to support the previous quantitative results by answering open-ended questions relating to how they used the PSVs, any technical (or other) problems they had encountered, and their suggestions for improving the study tools.

The surveys were administered to 44 students in an introductory engineering circuit analysis course but one student chose to not participate resulting in a total of 43 students participating in the evaluation. Of the 43 students participating in the study, there were 25 sophomores, 17 juniors, and 1 senior. All but 12 of the students had taken an engineering course prior to this study. The majority of the students reported they used the computer regularly in their courses with 35 using the computer daily in their courses while 6 used the computer weekly. One of the remaining two students reported they used the computer monthly while the other student reported they never used the computer in their courses.

The first data point that was needed before proceeding with this study was to make sure the students were using the PSVs. Proceeding each test, the students were asked how often they had used the PSVs as a study tool. Each time, the results were almost identical. Using the summative evaluation that was given at the end of the semester, the number of times the students reported using the PSVs as a study tool is given in Table 1.

Table 1. Frequency Students Reported Using PSVs

\begin{tabular}{|c|c|}
\hline Number of times & Frequency \\
\hline 0 & 2 \\
\hline $1-3$ & 7 \\
\hline $4-6$ & 10 \\
\hline $7-9$ & 8 \\
\hline+10 & 16 \\
\hline
\end{tabular}

These results indicated the students were using the PSVs for their studying purposes. To determine how the students were using the PSVs as a study tool, the five ways for which the PSVs had been developed were listed. The students were asked to check all of the different PSV options they had used to study the course material. A summary of their responses is given in Table 2.

Table 2. Use of PSVs as a Study Tool

\begin{tabular}{|l|c|}
\hline \multicolumn{1}{|c|}{ Options to use PSVs as a study tool } & Frequency* \\
\hline Homework from previous semester & 35 \\
\hline Homework from current semester & 34 \\
\hline Class examples from current semester & 30 \\
\hline Other examples not covered in class & 11 \\
\hline Previous test solutions & 24 \\
\hline
\end{tabular}

*Students could choose more than one response

With the exception of the "other examples not covered in class," the students were using all of the PSVs. In an effort to further explain the quantitative data summarized in Table 2, selected open-ended questions were used to determine how the students used the previous test and

"Proceedings of the 2005 American Society for Engineering Education Annual conference \& Exposition Copyright@ 2005, American Society for engineering Education", 
homework PSVs while studying for their tests and completing their homework. The results of how the students used the PSVs while studying for tests are provided in Table 3.

Table 3. How Students Used PSVs While Studying for Tests

\begin{tabular}{|l|c|}
\hline Task & Frequency \\
\hline $\begin{array}{l}\text { To get better understanding of the material by } \\
\text { working problems }\end{array}$ & 8 \\
\hline $\begin{array}{l}\text { To answer my questions instead of going to } \\
\text { the teacher }\end{array}$ & 4 \\
\hline To review more examples for practice & 17 \\
\hline To review previous tests & 6 \\
\hline $\begin{array}{l}\text { To refresh my memory on the material from } \\
\text { class }\end{array}$ & 3 \\
* Five students did not respond
\end{tabular}

Approximately half of the students (17 of the 36 students who responded to this question) were reviewing the previous test solutions as a method to practice more examples while they studied for the tests. This was providing the students assistance outside of class as they were studying the material at their own pace. An interesting point was that a few students (4 of 36) reported using the PSVs to answer questions that they normally would have had to ask the instructor outside of class and 3 of the students reported the PSVs were helpful to recall information that had been presented in class.

Even though the students reported using the PSVs while studying for tests, the majority of the students (30 of 43) reported using the PSVs mainly for figuring out how to solve their homework problems. The instructor's procedure for assigning homework was to give the final answer, but the homework solutions were not posted online until after the students turned in their worked homework problems. However, the homework PSVs from the previous semester, which required similar procedures to solve, were posted for the students to use while working their homework problems. To further investigate at what point the students were using the PSVs to help them work the homework problems, each of the 30 responses was categorized as either before, during, or after working the homework problems and the results are given in Table 4.

Table 4. When Students Used PSVs for Homework

\begin{tabular}{|l|c|}
\hline Task & Frequency \\
\hline Before working homework problems & 5 \\
\hline While working homework problems & 18 \\
\hline $\begin{array}{l}\text { After working homework to figure out what } \\
\text { was wrong or to compare procedures }\end{array}$ & 7 \\
\hline
\end{tabular}

Those students who reported using the PSVs prior to working the homework problems indicated they did so because they needed help getting started or did not understand the problem and were seeking more information so they could work the problem. The majority of the students used the PSVs while they were working the homework problems because they were either stuck or were seeking reassurance that their procedure for the working the problem was on the right track. Once again the students were exploring for themselves the resources needed to solve the problems as opposed to memorizing a problem as a means of trying to understand the

"Proceedings of the 2005 American Society for Engineering Education Annual conference \& Exposition Copyright@ 2005, American Society for engineering Education", 
concepts. Some students reported they worked the homework problems and then downloaded the previous semester's homework solution PSVs to compare the procedures for working the problems or to figure out what was wrong if their answer was incorrect.

Whether the student used the PSVs before, during, or after working the homework solutions or to study for the tests, the study tools encouraged the student to apply their problem-solving skills by learning how to apply the concepts to different problems. This led to investigate if the students were applying a step-by-step approach (which promotes problem solving) or were they reviewing the entire solution seeking a solution? The students were asked to rate on a scale of 1 to 4 ( 1 being disagree and 4 being agree) how each of the procedures listed in Table 5 applied to their own studying process.

Table 5. Students' Reported Procedures

\begin{tabular}{|l|c|}
\hline \multicolumn{1}{|c|}{ Procedure } & Average \\
\hline $\begin{array}{l}\text { Reviewed PSV numerous times using step- } \\
\text { by-step approach }\end{array}$ & 3.8 \\
\hline Reviewed entire PSV as needed & 2.2 \\
\hline $\begin{array}{l}\text { Reviewed entire PSV then step-by-step as } \\
\text { needed }\end{array}$ & 2.7 \\
\hline Reviewed entire PSV only once & 1.4 \\
\hline
\end{tabular}

The results in Table 5 suggest that the students were using the PSVs in a step-by-step approach in an effort to study the material and apply their own problem solving skills. With an average of 3.8/4.0, the procedure that best described the majority of the students' process for studying was to review the PSVs numerous times using a step-by-step approach as opposed to reviewing the entire PSV at once. The latter procedure would suggest the students would be reviewing the PSVs in an attempt to "find" the solutions whereas the students reported their preferred method was to apply a step-by-step approach which should result in better comprehension of the material.

As with any new instructional approach, there are always advantages and disadvantages each instructor must consider. Therefore, because the students were using the PSVs, what were their suggestions for improvement? The video quality and accessibility results are given in Table 6.

Table 6. Students' Ratings of PSV Quality

\begin{tabular}{|l|c|}
\hline \multicolumn{1}{|c|}{ Quality Item } & Average \\
\hline Picture quality & 3.0 \\
\hline Sound quality & 3.1 \\
\hline Accessibility via the Internet & 3.2 \\
\hline $\begin{array}{l}\text { Suitability of content via videos of problem } \\
\text { solutions }\end{array}$ & 3.2 \\
\hline
\end{tabular}

With an average of approximately 3 (Very Good) out of 4 (Excellent) for each of the quality factors, the students seemed satisfied with the quality of the study tools. However, there were some technical and user-friendly issues that the students encountered and, if corrected, could improve the PSVs. The students' responses when asked to list all of the technical (or other) problems they had experienced are categorized in Table 7.

"Proceedings of the 2005 American Society for Engineering Education Annual conference \& Exposition Copyright@ 2005, American Society for engineering Education” 
Table 7. Problems Students Experienced When Using PSVs

\begin{tabular}{|c|c|}
\hline Problem & Frequency* \\
\hline None & 23 \\
\hline Slow connection & 5 \\
\hline Large files and long downloads & 4 \\
\hline Files not compatible with Macintosh computer & 2 \\
\hline Must choose Windows media player each time & 2 \\
\hline $\begin{array}{l}\text { Explanations too fast and controls don't always } \\
\text { work to go back }\end{array}$ & 2 \\
\hline Files must be downloaded and then viewed & 1 \\
\hline
\end{tabular}

Basically, the majority of the students had not experienced any technical (or other) problems. Even though the frequency of the remaining items listed was low, each one provided a valuable suggestion for instructors to consider during the development stages of instructional aids of stepby-step solutions that will be used by students. The problems associated with the slow connections, large files, and compatibility issues should be investigated by the instructor as the software and equipment is being selected to create the study tools. The last open-ended question asked the students to list their suggestions for improving the PSVs. A categorized summary of their responses is given in Table 8 .

Table 8. Students' Suggestions for Improving Teaching Method

\begin{tabular}{|l|c|}
\hline \multicolumn{1}{|c|}{ Suggestion } & Frequency* \\
\hline None & 16 \\
\hline Higher quality PSVs (e.g. sound, picture) & 4 \\
\hline More examples as difficult as the homework & 3 \\
\hline $\begin{array}{l}\text { Improve how PSVs are viewed and controlled by } \\
\text { user }\end{array}$ & 3 \\
\hline Decrease file size & 3 \\
\hline $\begin{array}{l}\text { Slower and more in-depth answers with } \\
\text { reasoning behind each step }\end{array}$ & 3 \\
\hline Label PSVs more descriptively & 2 \\
\hline Make compatible for PC and Macintosh & 1 \\
\hline $\begin{array}{l}\text { Include section of PSV answering frequently } \\
\text { asked questions }\end{array}$ & 1 \\
\hline
\end{tabular}

*Students could provide more than one response

The majority of those students offering suggestions for improvement liked the PSVs as a study tool. Of the 16 who reported no suggestions, 7 of those added an additional comment indicating they felt the PSVs were already very good as they were. This indicated that even though there were some technical and user-friendly issues that can be corrected, the students liked the novel idea of having access to step-by-step solutions as a study tool that they could use at their own convenience outside of class and at their own pace. The two categories of suggestions relating to slower and more in-depth answers and a section of frequently asked questions suggest that those four students feel these are factors that would enhance their ability to better utilize the PSVs. But most importantly, did the students feel the use of the PSVs

"Proceedings of the 2005 American Society for Engineering Education Annual conference \& Exposition Copyright@ 2005, American Society for engineering Education", 
increased their understanding of the material? On a scale of 1 (Disagree) to 4 (Agree), the students responded with an average rating of 3.2 out of 4.0. Therefore, their overall experience using the PSVs was "very good".

In summary, the students reported they used the PSVs for completing their homework and studying for tests when they needed additional assistance outside of class. The majority of the students reported their study procedure was to review the PSVs numerous times in a step-by-step approach. This indicated that the study tools provided were being used by the students to enhance their problem solving skills on an individual basis. Therefore, the students could access the study tools at their convenience and use them at their own pace. The results from this study suggest that students can benefit if provided study aids that are designed to address their study procedures outside of class. Further investigations are needed to determine how students' learning styles can be used to develop study tools that will enhance the understanding of engineering material and provide the opportunity for students to develop their own problem solving skills. Finally, an evaluation of the students' test performance is needed to provide baseline data on whether their reported step-by-step study processes are being transferred when they solve problems.

References

1. Dick, W. and Carey, L. (1996) The Systemic Design of Instruction (4 ${ }^{\text {th }}$ ed.), Harper Collins, New York.

2. Gagne, R. M., Briggs, L. J., and Wager, W. W. (1992) Principles of Instructional Design (4 ${ }^{\text {th }}$ ed.). Harcourt Brace Jovanovich, New York.

3. National Research Council (1999) How people learn: Brain, mind, experience, and school, National Academy Press, Washington, DC.

4. Dufresne, R., Mestre, J., Hart, D., and Rath, K. (2002) "The effect of web-based homework on test performance in large enrollment introductory physics course," Journal of Computers in Mathematics and Science Teaching, 21(3), 229-251.

5. Jones, T. H., and Paolucci, R. (1999) "Research framework and dimensions for evaluating the effectiveness of educational technology systems on learning outcomes," Journal of Research on Computing in Education, 32(1), 1727.

6. Olsen, D. (1999). “Constructivist principles of learning and teaching methods,” Education, 120(2), $347-356$.

7. Ruhe, V. (2002) "Issues in the validation of assessment in technology-based distance and distributed learning: What can we learn from Messick's framework?” International Journal of Testing, 2(2), 143-159.

8. Dewey, J. (1933) How we think, Heath, New York.

9. Piaget, J. 1(1963). Origins of Intelligence in Children, Norton, New York.

10. Bruner, J. S. (1968) Toward a theory of Instruction, Norton, New York.

11. Kashy, E., Graff, S. J., Pawley, H., Stretch, W. L., and Wolfe, S. L. (1995) “Conceptual questions in computerassisted assignments," American Journal of Physics, 63(11), 1000-1005.

"Proceedings of the 2005 American Society for Engineering Education Annual conference \& Exposition Copyright@ 2005, American Society for engineering Education", 
12. Nelson, W. A., Bueno, K. A., and Huffstutler, S. (1999) "If you build it, they will come, but how will they use it?" Journal of Research on Computing in Education, 32(2), 270-286.

13. Nooriafshar, M. (2002) "Use of web-based multimedia technology in teaching and learning mathematical programming," Journal of Computers in Mathematics and Science Teaching, 21(4), 331-339.

14. Smith, S., and Stovall, I. (1996) "Networked instructional chemistry: Using technology to teach chemistry," Journal of Chemical Education, 73(3), 222-225.

15. Wells, K. L., \& Marsh, L. C. (1997) “Key aspects of a computerized statistics course,” Journal of Computing in Higher Education, 8(2), 72-93.

R. M. NELMS received the B.E.E. and M.S. degrees in electrical engineering from Auburn University, AL in 1980 and 1982, respectively. He received the Ph.D. degree in electrical engineering from Virginia Polytechnic Institute and State University, Blacksburg, VA in 1987. He is presently a Professor in the Department of Electrical and Computer Engineering at Auburn University.

R. F. HALPIN received from Auburn University the B.S. degree in applied mathematics in 1988 and the M.Ed. and Ph.D. Degrees in secondary mathematics education in 1990 and 1994, respectively. She is currently an independent consultant conducting program evaluations and assessments of various projects. Her research interests are in educational technology and secondary mathematics education. 